\title{
MAPEAMENTO DAS ÁREAS DE FRAGILIDADE DA RPPN FOZ DO RIO AGUAPEÍ/SP
}

\section{MAP OF FRAGILITY AREAS AT THE MOUTH OF RIVER AGUAPEÍ/SP}

Patrícia Felipe de Moura ${ }^{1 ;}$ Renata Ribeiro de Araújo $^{2}$

Universidade Estadual Paulista - UNESP, Presidente Prudente, SP. e-mail: reribeiro@fct.unesp.br

RESUMO - A presente pesquisa buscou através de mapeamento localizar e espacializar as áreas de fragilidade na região da foz do rio Aguapeí. Para alcançar o objetivo utilizou-se da metodologia proposta por Ross (1994): Análise Empírica da Fragilidade dos Ambientes Naturais e Antropizados. A metodologia propôs análises do relevo, uso e cobertura do solo e tipos de solo, permitindo espacializar e identificar as áreas de maior fragilidade na região do estudo. Foram utilizados mapas temáticos de declividade, uso e cobertura e solos através do software SPRING/INPE versão 5.2 no qual foi realizado o SIG (Sistema de Informações Geográficas) e gerado o mapa de fragilidade, o qual qualificou as áreas de fragilidade em muito fraca, fraca, média, forte e muito forte.

Palavras-chave: Rio Aguapeí; fragilidade; mapeamento.

ABSTRACT - The present scientific research mapped, localized and spatialized the fragility areas at the mouth of river Aguapeí. To reach the objective was used the Ross' (1994) methodology: Empirical analysis of the fragility of natural environments and occupied by man. The methodology proposed analysis about topography, land's use and cover and soil types, this way was possible espatialize and identify the areas of major fragility at the area of study. Maps of slope, land's use and cover and soils although the software SPRING/INPE version 5.2. In SPRING was made the GIS (Geographic Information Systems) and the fragility's map. The fragility's map classified the fragility areas into very weak, weak, medium, strong, very strong.

Keywords: River Aguapeí; fragility; map.

Recebido em: 12/08/2014

Revisado em: 20/08/2014

Aprovado em: 01/09/2014 


\section{INTRODUÇÃO}

Desde o século passado o homem vem alterando as tecnologias no meio social, na economia e, especialmente, no meio ambiente. Frente a estas mudanças, a natureza dá diferentes respostas de acordo com maior ou menor grau de fragilidade, diretamente relacionado às suas características de formação (SPÖRL; ROSS, 2004).

Segundo Spörl (2007), fragilidade ambiental é compreendida como o grau de susceptibilidade a danos como erosão, desmoronamentos, assoreamento de cursos d'água e inundações.

O conhecimento das potencialidades dos recursos naturais de um sistema natural passa pelos levantamentos dos solos, relevo, geologia, águas, clima e todos os componentes do estrato geográfico que dão suporte a vida. Assim, para analisar a fragilidade ambiental de um determinado local deve-se estudar as variáveis mencionadas de forma integrada (ROSS, 2000).

Baseado no conceito preconizado por Tricart (1977) de Unidades Ecodinâmicas, Ross (apud ROSS, 2000) inseriu novos critérios para a análise dos ambientes, transformando-os em Unidades Ecodinâmicas Estáveis e Unidades Ecodinâmicas Instáveis.

As Unidades Ecodinâmicas Estáveis ou Unidades Ecodinâmicas de Instabilidade
Potencial são aquelas que ainda não sofreram processos antropogênicos e, assim, encontram-se em equilíbrio dinâmico, porém possuem instabilidade potencial qualitativamente previsível de acordo com suas características naturais e a possível intervenção humana. As Unidades Ecodinâmicas Instáveis ou Unidades Ecodinâmicas de Instabilidade Emergente, são aquelas cujo homem alterou profundamente através de, por exemplo, queimadas e desmatamentos (ROSS, 1994).

Para que os conceitos criados por Ross (apud ROSS, 2000) pudessem ser aplicados ao planejamento ambiental, ele criou cinco graus de instabilidade variando de "muito fraca" a "muito forte".

De acordo com Spörl, Castro e Luchiari (2011) os mapeamentos da fragilidade ambiental vêm se tornando fundamental, visto que, os conhecimentos a respeito da dinâmica do sistema e as transformações dele decorrentes são importantes para auxiliar nas tomadas de decisão das ações prioritárias, a fim de garantir a qualidade dos recursos hídricos e do solo.

Os mapas são excelentes ferramentas para aquisição de informações espaciais sobre os atributos de uma determinada área, isso porque alguns tipos de mapeamentos utilizam imagens de satélite o que facilita e barateia o estudo (GONÇALVES, 2013, p.13). Nos estudos ambientais envolvendo bacias hidrográficas, 
segundo o mesmo autor, o sensoriamento remoto se mostra um ótimo instrumento visto que através dele as imagens de satélites são aplicadas para geração de mapas. As informações podem ser extraídas através da interpretação de imagens multiespectrais, gerando classes, feições, objetos, etc.

Desta forma, os mapas são ótimos instrumentos para fundamentar e nortear estudos na área ambiental a fim de possibilitar tomadas de decisão corretas no que se trata de políticas de gerenciamento de recursos naturais.

\section{OBJETIVO}

Mapear e analisar os atributos do meio físico do ambiente fluvial e espacializar as regiões de maior instabilidade ambiental na RPPN Foz do Aguapeí/SP.

\section{METODOLOGIA}

Foram levantados dados físicos do local de estudo como geologia, topografia e geomorfologia, hidrografia e solos baseados em mapas e em cartas topográficas préexistentes.

Para extração de informações temáticas (relevo, uso/manejo do solo e tipos de solo) todos os conjuntos de dados espaciais foram projetados para um único sistema de coordenadas geográficas, de fuso, e Datum.
O tratamento das imagens obtidas livres (LandSat) adquiridas no sitio do INPE e imagens BING foram executados com 0 auxílio de software SIG (Sistemas de Informação Geográfica) específico (SPRING/INPE) e utilizado para os mapeamentos e o zoneamento.

Para processamento das imagens primeiramente foi necessário criar um banco de dados e um projeto, posteriormente as imagens foram importadas para o software e georreferenciadas e por meio de teste descobriu-se a melhor composição colorida para sua posterior classificação.

A confecção do mapa de delimitação da área da foz do rio Aguapeí foi realizada utilizando imagens do satélite LandSat8 (órbita/ponto - 223/075) do dia 22 de abril de 2013 obtidas no site http://earthexplorer.usgs.gov/ após efetuar o Login, preencheu-se a lacuna de datas com a data 04/22/2013, na aba "data sets" selecionou-se o LandSat Archive e dentro dele o L8 OLI/TIRS e na aba "Aditional Criteria" as lacunas WRS Path e WRE Row foram preenchidas respectivamente com os números 223 e 075, após isso se clicou em "Results" e na opção de download e os dados foram trabalhados no programa SPRING 5.2.4.1 64bits.

Para a análise da fragilidade ambiental foram utilizados os mapas de declividade, de solos e de uso e cobertura da 
terra. O mapa de uso e cobertura utilizado foi o elaborado por Domingues (2012). Para a elaboração do mapa temático de declividade, utilizou-se de uma grade altimétrica (1:10000) elaborada por Domingues (2012). O mapa de solos da área de estudo utilizado foi o elaborado por Suizu e Rocha (2013).

Os mapas foram divididos em classes e a estas classes foram dados pesos variando de 1 a 5 conforme maior ou menor grau de proteção/fragilidade da área. Seguindo a metodologia sugerida por Ross (1994), o mapa de declividade foi divido em classes como mostrado na tabela 1 que, segundo o autor, são classes consagradas nos estudos de capacidade de uso/aptidão agrícola, associadas ao vigor dos processos erosivos, dos riscos de escorregamento/deslizamentos e inundações frequentes.

Tabela 1. Classes de declividades

\begin{tabular}{|l|l|}
\hline \multicolumn{1}{|c|}{ Categorias } & \multicolumn{1}{c|}{$\%$} \\
\hline - Muito Fraca & Até $6 \%$ \\
\hline 2 - Fraca & De 6 a $12 \%$ \\
\hline 3 - Média & De 12 a $20 \%$ \\
\hline 4 - Forte & De 20 a $30 \%$ \\
\hline 5 - Muito Forte & Acima de $30 \%$ \\
\hline
\end{tabular}

Fonte: (Ross, 1994, p. 66)

Ross (1994) classificou a fragilidade dos solos conforme apresentado na tabela 2.
Tabela 2. Classes de fragilidade dos tipos de solos

\begin{tabular}{|l|l|}
\hline $\begin{array}{l}\text { Classes de } \\
\text { Fragilidade }\end{array}$ & \multicolumn{1}{|c|}{ Tipos de Solos } \\
\hline $\begin{array}{l}\text { 1 - Muito } \\
\text { Baixa }\end{array}$ & $\begin{array}{l}\text { Latossolo Roxo, Latossolo } \\
\text { Vermelho Escuro e Vermelho } \\
\text { Amarelo, textura argilosa. }\end{array}$ \\
\hline 2 - Baixa & $\begin{array}{l}\text { Latossolo Amarelo e Vermelho } \\
\text { Amarelo, textura } \\
\text { média/argilosa. }\end{array}$ \\
\hline 3 - Média & $\begin{array}{l}\text { Latossolo Vermelho Amarelo, } \\
\text { Terra Roxa, Terra Bruna, } \\
\text { Podzólico Vermelho Amarelo } \\
\text { textura média/argilosa. }\end{array}$ \\
\hline 4 - Forte & $\begin{array}{l}\text { Podzólico Vermelho Amarelo } \\
\text { textura média/arenosa, } \\
\text { Cambissolos. }\end{array}$ \\
\hline 5 - Muito & $\begin{array}{l}\text { Podzolizados com cascalho, } \\
\text { Litólicos e Areias } \\
\text { Quartzarenicos }\end{array}$ \\
\hline
\end{tabular}

Fonte: (Ross, 1994, p. 68)

De acordo com pesquisas realizadas por Trombeta et al. (no prelo), os solos encontrados na área de estudo são: Argissolos Vermelho-Amarelos possuem fragilidade média e Gleissolo Háplico, muito alta (por se localizar em planície de inundação). Desta maneira o a classificação da fragilidade dos solos utilizada foi a classificação adaptada conforme Trombeta et al. (no prelo).

Quanto aos graus de proteção devido à cobertura vegetal Ross (1994) elaborou a tabela 3 mostrando os graus de proteção de áreas naturais e áreas antropizadas. 
Tabela 3. Graus de proteção por tipos de cobertura vegetal

\begin{tabular}{|c|c|}
\hline $\begin{array}{l}\text { Graus de } \\
\text { Proteção }\end{array}$ & Tipos de Cobertura \\
\hline $\begin{array}{l}1 \text { - Muito } \\
\text { Alta }\end{array}$ & $\begin{array}{l}\text { Florestas/Matas naturais, } \\
\text { florestas cultivadas com } \\
\text { biodiversidade. }\end{array}$ \\
\hline 2 - Alta & $\begin{array}{l}\text { Formações arbustivas naturais } \\
\text { com estrato herbáceo denso. } \\
\text { Formações arbustivas densas } \\
\text { (mata secundária, cerrado denso, } \\
\text { capoeira densa). Mata } \\
\text { homogênea de Pinus densa. } \\
\text { Pastagens cultivadas sem } \\
\text { pisoteio de gado. Cultivo de ciclo } \\
\text { longo como o cacau. }\end{array}$ \\
\hline 3 - Média & $\begin{array}{l}\text { Culturas de ciclo longo em curvas } \\
\text { de nível/terraceamento como } \\
\text { café, laranja com forrageiras } \\
\text { entre ruas. Pastagens com baixo } \\
\text { pisoteio. Silvicultura de } \\
\text { eucaliptos com sub-bosque de } \\
\text { nativas. }\end{array}$ \\
\hline 4 - Baixa & $\begin{array}{l}\text { Culturas de ciclo longo de baixa } \\
\text { densidade (café, pimenta-do- } \\
\text { reino, laranja) com solo exposto } \\
\text { entre ruas, culturas de ciclo curto } \\
\text { (arroz, trigo, feijão, soja, milho, } \\
\text { algodão) com cultivo em curvas } \\
\text { de nível/terraceamento. }\end{array}$ \\
\hline $\begin{array}{l}5 \text { - Muito } \\
\text { Baixa }\end{array}$ & $\begin{array}{l}\text { Áreas desmatadas e queimadas } \\
\text { recentemente, solo exposto por } \\
\text { arado/gradeado, solo exposto ao } \\
\text { longo de caminhos e estradas, } \\
\text { terraplenagens, culturas de ciclo } \\
\text { curto sem práticas } \\
\text { conservacionistas. }\end{array}$ \\
\hline
\end{tabular}

Fonte: (Ross, 1994, p.68)

Para padronizar os mapas adaptou-se a metodologia de Ross (1994) atribuindo-se pesos para as classes variando de 0 a 1 , de acordo com as características de cada mapa.

No mapa de declividade, os pesos variaram de " 0,1 " a "0,9", com variância de
“0,2" entre as classes, do menor grau de fragilidade ou menor potencial erosivo declividade de até $6 \%$ - para o maior declividades acima de $30 \%$.

Na padronização do mapa de uso e cobertura, também de 0 a 1, deu-se menor peso para locais com maior proteção como locais de "reflorestamento" que, por apresentarem menor fragilidade, receberam pesos iguais a " 0,3 ", já áreas com menor proteção como "áreas abertas/pastagens/gramíneas" que apresentam maior fragilidade receberam pesos mais altos, " 0,7 ".

No mapa de solos, o critério para escolha dos pesos passou pelos estudos de Trombeta et al. (No prelo), enquadrando os solos da área de estudo nas classes de fragilidade média, no caso do Argissolo Vermelho-Amarelo, tendo peso 0,5, e fragilidade muito forte, no caso do Gleissolo Háplico, tendo peso 0,9.

Com os planos de informação concretizados utilizou-se o Método AHP (Processo Analítico Hierárquico) onde com auxilio da opção suporte à decisão AHP do Spring 5.2 atribuíram-se pesos aos planos padronizados.

Os pesos escolhidos para os Planos de Informação se basearam na metodologia de Massa e Ross (2012, p.63) que considera “(...) os seguintes parâmetros por ordem de importância: 1.ㅇ - O relevo (tipos de 
vertentes e índices de dissecação); 2. - O tipo de solo e 3. - Grau de proteção do solo em função da cobertura vegetal e tipos de uso da terra." Nesta pesquisa, utilizou-se a declividade para estudo do relevo.

Confirmado o valor elaborou-se um modelo numérico do terreno (MNT) com as áreas de fragilidade ambiental através da interface "Legal" seguindo o algoritmo criado pelo método AHP.

Após a geração do MNT, realizou-se o fatiamento utilizando as classes definidas por Ross (2000): Muito Fraca, Fraca, Média, Forte e Muito Forte.

\section{RESULTADOS}

A área de estudo, figura1, encontra-se no baixo Aguapeí, que nasce em Gália e percorre $416 \mathrm{~km}$ até sua foz, passando por 58 municípios onde vivem cerca de 320.000 habitantes, que tem por base da sua economia principalmente a agropecuária, agricultura e indústrias de pequeno porte. A vazão líquida do rio varia de $1206 \mathrm{~m}^{3} / \mathrm{s}$, para máxima, e $35,18 \mathrm{~m}^{3} / \mathrm{s}$, para mínima (FIGUEIREDO, 2007).

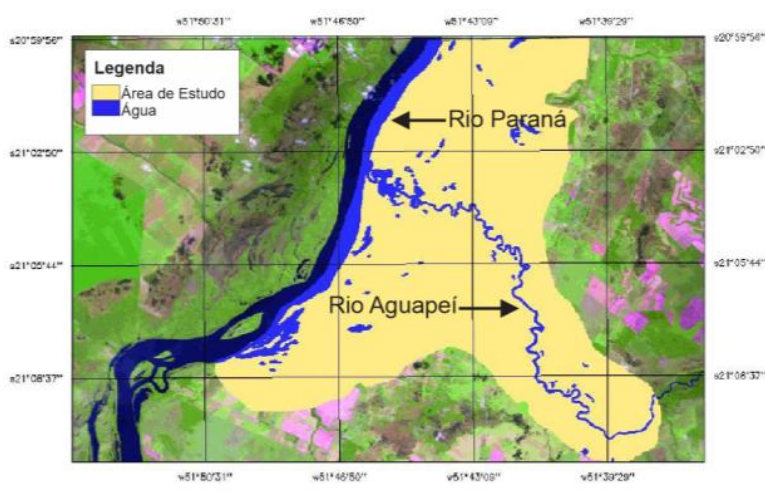

Figura 1. Área de estudo Fonte: Autor

A região é constituída por rochas vulcânicas e sedimentares da Bacia do Paraná de idade mesozoica e depósitos aluvionares de idade cenozoica, composta pela formação Santo Anastácio (Ksa - arenitos muito finos a médios, mal selecionados, subordinadamente de caráter arcosiano, geralmente maciços, apresentando localmente cimento e nódulos carbonaticos) e, predominantemente, por sedimentos aluvionares (Qa - aluviões em geral, incluindo areias inconsolidadas de granulação variável, argilas e cascalheiras subordinadamente, em deposito de calha e/ou terraços) (CBH-AP, 1997).

Quanto à geomorfologia da região, grande parte pertence às Bacias Sedimentares Cenozoicas, que são caracterizadas por planícies e terraços fluviais com baixas declividades, sujeitos a inundações periódicas. Também possui uma pequena porção inserida sobre a Bacia Sedimentar do Paraná, que como 
característica formas pouco dissecadas a planas, com vales pouco entalhados e dimensão interfluvial muito grande, sendo assim com baixo potencial erosivo. Outra pequena área é caracterizada por formas muito dissecadas e pequena dimensão interfluvial, com grande possibilidade de geração de processos erosivos agressivos (SUIZI; ROCHA, 2013).

Como produto intermediário obtevese 0 mapa de declividade, figura 2, mostrando os locais com maior potencial erosivo.

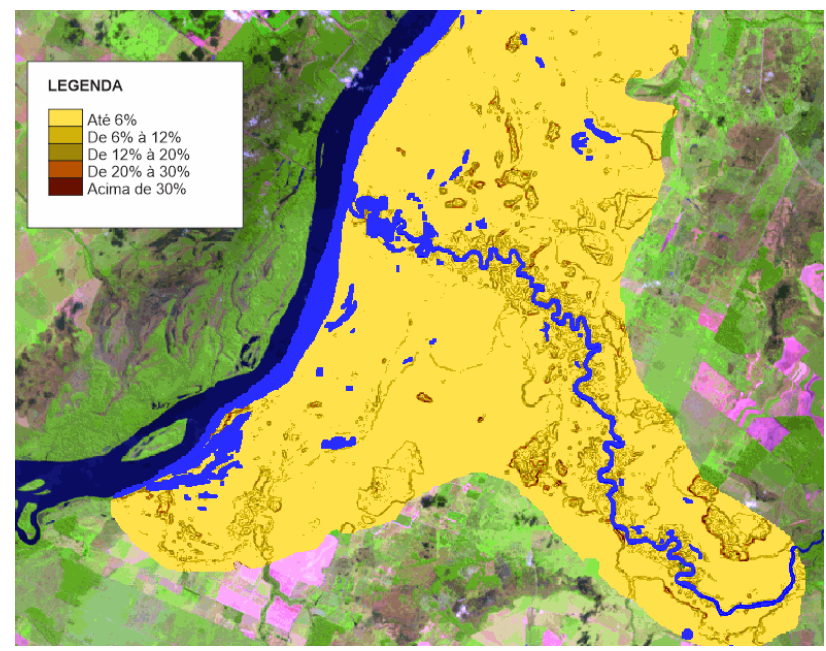

Figura 2. Mapa de declividade

Fonte: Autor

No mapa de declividade é observado que o local é muito plano, possuindo poucos locais com declividades que representem grandes problemas quanto a fragilidade.

Outro produto intermediário obtido foi o mapa de uso e cobertura do solo, figura 3, que identificou os principais tipos de uso da terra na área de estudo.

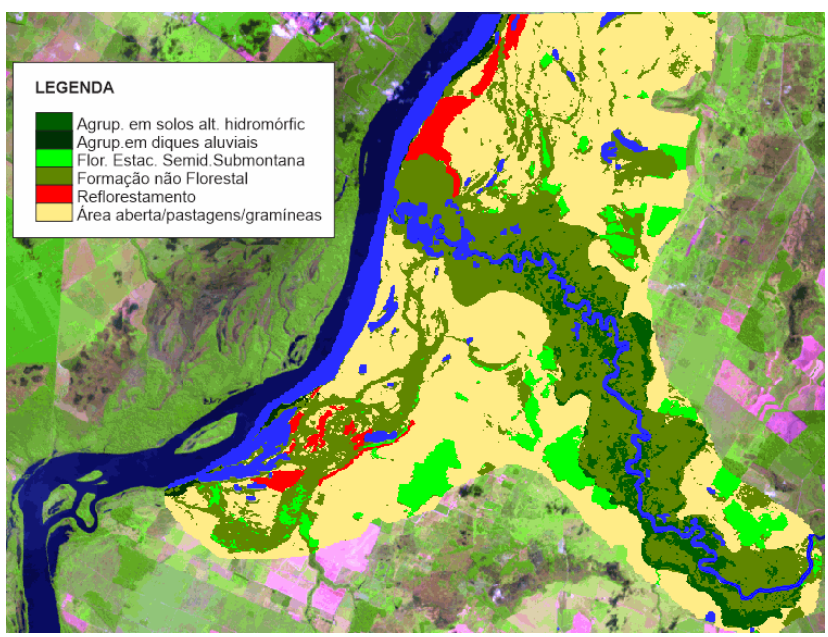

Figura 3. Mapa de uso e cobertura do solo

Fonte: Adaptado de Domingues (2012)

Pode-se notar que grande parte da área de estudo é constituída por pastagens, gramíneas e áreas abertas, e próximo ao rio Aguapeí há formações não florestais que fornecem proteção maior ao solo.

O mapa de solos, figura 4 , mostrou a existência de dois tipos de solos na região, o Gleissolo Háplico e o Argissolo VermelhoAmarelo.

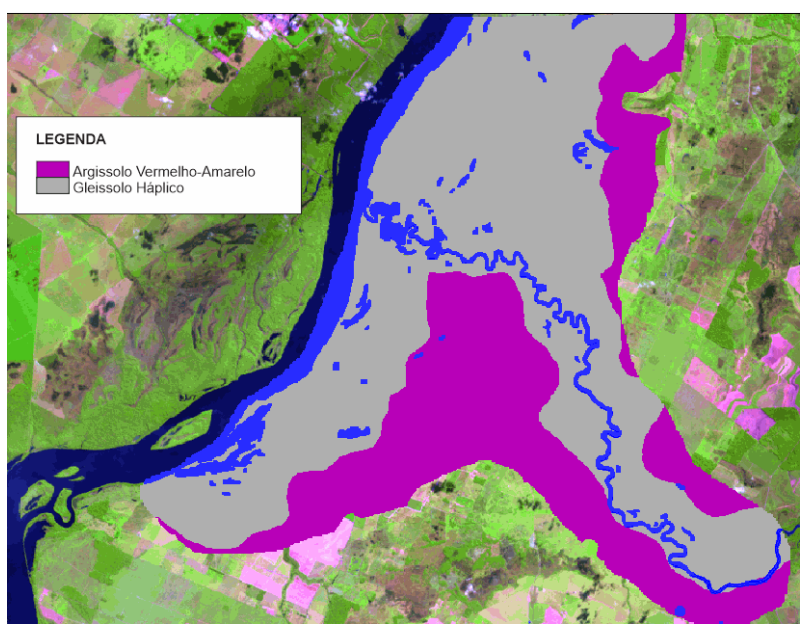

Figura 4. Mapa de solos

Fonte: Adaptado de Suizi e Rocha (2013)

Após a análise pelo método AHP, obteve-se a geração de um MNT e 
posteriormente ao fatiamento obteve-se 0 mapa final de fragilidade, figura 5.

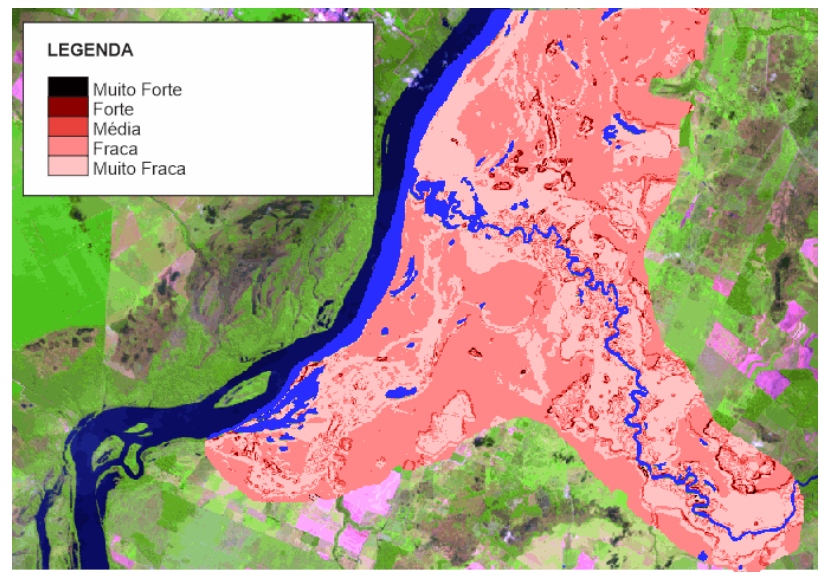

Figura 5. Mapa final de fragilidade

Fonte: Autor

\section{DISCUSSÃO}

Observando o mapa de fragilidade pode-se notar que as áreas classificadas com fragilidade muito alta, alta e média são áreas caracterizadas por declividades mais elevadas, podendo ser antropizadas ou não e com ambos os tipos de solos. A metodologia propõe que o plano de informação que contem a declividade tenha mais peso que os outros, assim, caracterizando estas áreas, de declividades elevadas, como as mais frágeis, sugerindo que se mantenha sua cobertura vegetal para minimizar os efeitos causados pela erosão.

As áreas de fragilidade fraca se localizam na maior parte da área de estudo, sendo caracterizada por declividades baixas, variação do tipo de solo e, em geral, áreas de uso para pastagens, gramíneas ou áreas abertas.
Declividades, em geral, baixas e cobertura vegetal florestal ou não florestal, sem interferência humana, caracterizam as áreas de fragilidade muito fraca, quanto aos solos não possuem muita influência devido à proteção exercida pela cobertura vegetal e as baixas declividades que diminuem os efeitos da erosão.

Pode-se notar que o fator que mais influenciou na identificação das áreas de fragilidade foi a declividade como sugere a metodologia utilizada, porém viu-se também que os outros fatores influenciaram no grau de intensidade da fragilidade. A cobertura vegetal, por exemplo, foi fator determinante na distinção entre as áreas de fragilidade fraca e muito fraca.

Os tipos de solo pouco influenciaram a composição do mapa final, mas é importante lembrar que se retirada a cobertura vegetal em um local de solo frágil como o Gleissolo Háplico as chances de ter problemas com erosão aumentam consideravelmente.

Deste modo, torna-se imprescindível a observação das características naturais de uma região no momento da escolha das atividades a serem exercidas em um local e, como mostrado neste estudo, o mapa de fragilidade ambiental é um bom instrumento para análise de tais características.

Na RPPN Foz do Aguapeí/SP, notamos que as baixas declividades aliadas a 
vegetação próxima ao rios conferem baixos níveis de fragilidade para o local, fazendo com que o solo seja preservado, evitando maiores problemas com erosão e assoreamento de rios.

\section{CONSIDERAÇÕES FINAIS}

A partir dos estudos realizados na região da foz do rio Aguapeí, constatou-se que a região, em geral, possui fragilidade baixa ou muito baixa, isto se deve ao fato de estar localizada em um local de declividade baixa e por possuir área significativa coberta por formações florestais e não florestais. As regiões antropizadas, utilizadas para pastagens, com gramíneas ou áreas abertas, também não apresentaram grande problemas quanto erodibilidade visto que as declividades são baixas em sua maioria.

As áreas que apresentaram fragilidade muito alta, alta e média representam pequenas áreas, contudo necessitam de atenção especial no momento da sua utilização sendo aconselhável que se mantenham preservadas.

\section{AGRADECIMENTOS}

Ao CNPq, processo no 27520, pela bolsa de iniciação científica.

\section{REFERÊNCIAS}

CBH-AP. Relatório de situação dos recursos hídricos das bacias dos Rios Aguapeí e Peixe. 1997.
DOMINGUES, M. Classificação da cobertura da terra da RPPN "Foz do Rio Aguapeí": abordagem booleana para a integração de imagens TM-Landsat e dados multifonte. Presidente Prudente: [s.n], 2012.

FIGUEIREDO, A. G. O Processo de transporte e deposição de sedimentos nas calhas fluviais dos tributários laterais ao reservatório da hidrelétrica Sérgio Motta, Rio Paraná, Brasil. In: SIMPÓSIO BRASILEIRO DE RECURSOS HÍDRICOS - SIMPÓSIO DE HIDRÁULICA E RECURSOS HÍDRICOS DOS PAÍSES DE LÍNGUA OFICIAL PORTUGUESA, 17., 2007. ANAIS... Porto Alegre: $A B R H, 2007$.

GONÇALVES, S. R. A. Estudos limnológicos para mapeamento e monitoramento de canais da bacia hidrográfica do rio Santo Anastácio/SP. 2013. 71 f. Monografia (Graduação) - Faculdade de Ciências e Tecnologia, Universidade Estadual Paulista, Presidente Prudente - SP.

MASSA, E. M.; ROSS, J. L. S. Aplicação de um modelo de fragilidade ambiental relevo-solo na Serra da Cantareira, bacia do Córrego do Bispo, São Paulo-SP. Revista do Depto. De Geografia - FFLCH-USP, São Paulo, v. 24, p. 57-79, 2012. Disponível em: <http://www.revistas.usp.br/rdg/article/view /52754/56609>

ROSS, J. L. S. Análise empírica da fragilidade dos ambientes naturais e antropizados. Revista do Depto. De Geografia - FFLCH-USP, São Paulo, v. 8, p. 63-74, 1994.

ROSS, J. L. S. Geomorfologia aplicada aos EIAs. In: GUERRA, A. J. T.; CUNHA, S. B. Geomorfologia e meio ambiente. 3. ed. Rio de Janeiro: Bertrand Brasil, 2000. p.291-336.

SPÖRL, C.; CASTRO, E. G.; LUCHIARI, A. Aplicação de redes neurais artificiais na construção de modelos de fragilidade ambiental. Revista do Depto. De Geografia - 
FFLCH-USP, São Paulo, v. 21, p. 113-135, 2011.

SPÖRL, C. Metodologia para elaboração de modelos de fragilidade ambiental utilizando redes neurais. 185 f. 2007. Tese (Doutorado) - Programa de Pós-Graduação em Geografia, Universidade de São Paulo, São Paulo -SP.

SPÖRL, C.; ROSS, J.L.S. Análise comparativa da fragilidade ambiental com aplicação de três modelos. Revista GEOUSP: Espaço e tempo, São Paulo, n. 15, p. 39-49, 2004.

SUIZU, T.M.; ROCHA, P.C. Compartimentação geomorfológica e levantamento do meio físico na região da foz do rio Aguapeí, Oeste Paulista. 2013. Publicação eletrônica [mensagem pessoal]. Mensagem recebida por<patriciafmoura@outlook.com> em: 06 jun. 2014.

TRICART, J. Ecodinâmica. Rio de Janeiro: SUPREN/IBGE, 1977. $91 \mathrm{p}$.

TROMBETA, L.R. et al. Análise da fragilidade ambiental da unidade de gerenciamento de recursos hídricos Pontal do Paranapanema, São Paulo, Brasil. No prelo. 